\title{
Foot static disturbances and clinical features in overweight patients with rheumatoid arthritis
}

\author{
Anna Kuryliszyn-Moskal ${ }^{1}$, Anna Hryniewicz², Norbert Bagiński², Diana Moskal-Jasińska ${ }^{3}$, \\ Zofia Dzięcioł-Anikiej' ${ }^{1}$, Janusz Dzięcioł
}

\author{
${ }^{1}$ Department of Rehabilitation, Medical University of Bialystok, Poland \\ 2Physiotherapeutic practice, Tilburg, Holland \\ ${ }^{3}$ Department of Clinical Phonoaudiology and Speech Therapy, Medical University \\ of Bialystok, Poland \\ ${ }^{4}$ Department of Human Anatomy, Medical University of Bialystok, Poland
}

Submitted: 5 July 2019

Accepted: 8 December 2019

Arch Med Sci

DOI: https://doi.org/10.5114/aoms.2020.94971

Copyright @ 2020 Termedia \& Banach

\begin{abstract}
Introduction: Rheumatoid arthritis (RA) is a chronic, inflammatory, connective tissue disease, leading to foot deformities, impairment of locomotive functions, and reducing patients' quality of life. Obesity prevalence is rising in early RA and is associated with worse disease activity, function and health-related quality of life, with a significant negative impact on achieving a low Disease Activity Score in 28 joints (DAS28). The aim of the study was to evaluate foot deformities in overweight RA patients according to the severity of the disease.

Material and methods: The study was performed on 50 overweight women with RA. The control group consisted of 50 overweight women free of any disorders. Plantography examination was carried out by means of a CQ ST 2K podoscope. Rheumatoid arthritis disease activity was assessed by DAS28. Activity limitation was assessed using the Health Assessment Questionnaire (HAQ) and foot posture by the Foot Posture Index (FPI-6). Body composition analysis was performed using In Body 220.

Results: Hallux valgus was the most frequent deformation in RA patients with overweight. Longitudinal flat foot was much more frequent in RA patients than transverse flat foot. A relationship between fat tissue mass and presence of transverse flat foot in RA patients with overweight was found. In this group DAS28, VAS, and Clarke's angle were correlated with increased value of $\mathrm{HAQ}$.

Conclusions: Plantar contourography showed a trend of an increase of $\alpha$ angle values and the Sztriter-Godunow index (KY) in overweight RA patients with increasing severity of radiological changes and DAS28, requiring use of proper prevention and therapeutic strategies of destructive changes.
\end{abstract}

Key words: podoscopy, overweight, rheumatoid arthritis.

\section{Introduction}

Rheumatoid arthritis (RA) is a chronic systemic inflammatory disorder that may affect many tissues and organs but principally attacks the joints, producing a nonsuppurative proliferative and inflammatory synovitis that often progresses to destruction of the articular cartilage and ankyloses of the joints. About $1 \%$ of the world's population is afflict-
Corresponding author: Zofia Dzięcioł-Anikiej Department of Rehabilitation Medical University of Bialystok 24A M.C. Skłodowskiej St 15-276 Bialystok, Poland Phone: +48-85-7468482 Fax: +48-85-7468606 E-mail: dzieciol.zofia@gmail.com 
ed by RA, women two to three times more than men [1]. Symptoms usually develop in small bones of the hands and feet followed by the wrists, ankles, elbows, and knees [2].

Deformities as a consequence of the inflammatory process in the proximal interphalangeal and metatarsophalangeal joints of the feet are often observed at the time of initial diagnosis, problems with foot pain being a common complaint [2]. Also, disturbances of postural stability in patients with RA are often observed [3].

Different factors influence the structure and function of the foot; one of them is body mass [4-6].

Obesity prevalence is rising in the early phase of RA and is associated with an increased Disease Activity Score in 28 joints (DAS28) and significantly reduces everyday activity of patients [7-11]. Patients with high body mass index (BMI) values have higher disease activity, a worse response to treatment, and more extensive disability $[9,11-$ 14]. In women, obesity has been associated with higher risk of RA [8, 9].

The examination of a dependence between overweight and obesity and postural changes in the feet of RA patients seems to be a proper direction in the search for a preventive strategy and improvement of the quality of life of this population [15].

The aim of the study was to evaluate the degree of foot deformities and static disturbances in overweight patients with RA, in correlation with DAS28, BMI, the Foot Posture Index (FPI-6), and Health Assessment Quality (HAQ).

\section{Material and methods}

The examinations were carried out in the Department of Rehabilitation, the Department of Endocrinology, Diabetology and Internal Medicine of the Medical University of Bialystok. The research was approved by the Local Bioethical Commission of the Medical University of Bialystok.

The experimental group consisted of 50 overweight women $(25$ < BMI values < 30$)$ with RA at the ages of 32-69 (the average age was 57.46 \pm 9.56 years). Patients were divided into subgroups depending on radiological evaluation according to Steinbrocker's classification and DAS28.

The duration of RA ranged between 2 and 21 years (average $12.5 \pm 7.5$ years). Treatment included methotrexate (MTX) 15-20 mg once a week and folic acid $15 \mathrm{mg}$ once a week (given on the day after MTX administration).

Steroids and immunosuppressive drugs were not used during the two months prior to the study.

Fifty healthy overweight women $(25<\mathrm{BMI}$ values < 30) participated in the study as a control group. Their age ranged from 31 to 61 years (the average age was $42.20 \pm 8.34$ years).

To evaluate the presence of static foot changes we applied a podoscope with spatial scanner and computer-aided foot examination software CQ ST2K (Poland).

The following parameters, indicating foot deformity, were determined (Figure 1):

- Hallux valgus angle $(\alpha)$ (the angle between a tangential line of the medial edge of the foot and a tangential line from the widest part of the forefoot to the outside edge of the hallux). The norm is $0-9^{\circ}$.

- The Sztriter-Godunow factor (KY) represents the proportion of the length of the segment located in the foot arch centre (blackened area) and the length of the segment marked by the unblackened part of the plantar contourograph, $[K Y=(W-i) /(j-I)]$.
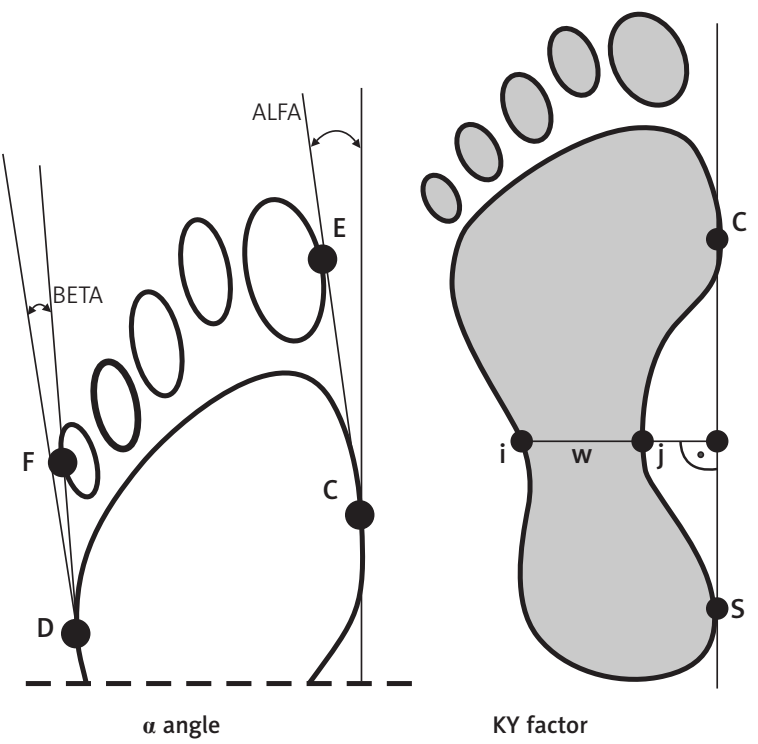

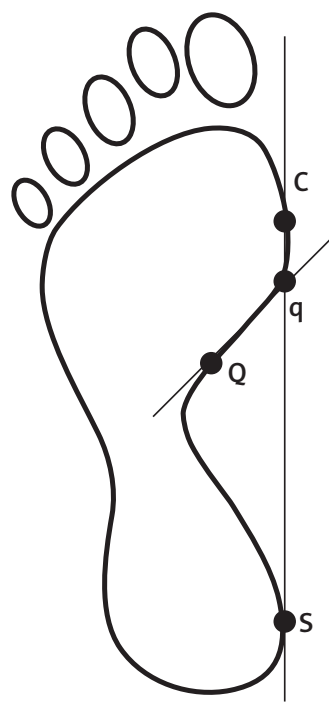

$\mathrm{CL}$ angle

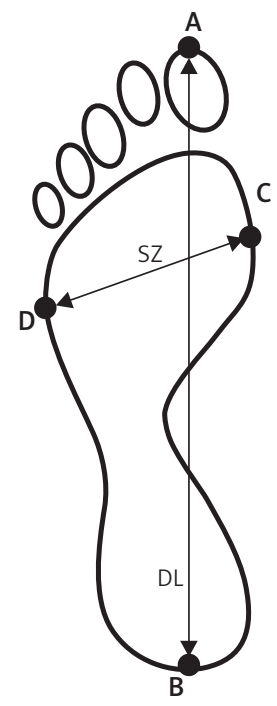

W factor

Fig. 1. Parameters determining foot deformities 
- The Wejsflog index (W) estimates the proportion between the length and width of the foot. Its normal proportion is $3: 1$.

- Clarke's angle (CL) - measurement of this index involves marking a straight line that joins the most internal points of the forefoot and the rearfoot and internal line $(\mathrm{Q}-\mathrm{q})$. The interpretation of the value of Clarke's angle: flat foot $\leq 30^{\circ}$, foot with a lower arch $31-41^{\circ}$, foot with a normal arch $42-54^{\circ}$, foot with a higher $\operatorname{arch} \geq 55^{\circ}$.

Disease activity of RA was measured by the DAS28, and intensity of pain by the visual analogue scale (VAS).

The Foot Posture Index (FPI-6) is designated for foot posture evaluation based on palpation of the head of the talus, curvatures above and below the lateral malleolus, position of the calcaneus in the frontal plane, prominence in the talonavicular joint, the medial longitudinal arch's congruence, and abduction/adduction of the forefoot on the rearfoot.
Body composition analysis was performed using In Body 220 (Biospace). Bioelectrical impedance is a non-invasive method of measuring body composition.

According to the World Health Organization, BMI values below 18.5 indicate underweight, values between 18.5 and 24.9 indicate normal weight, values $25<30$ indicate overweight, and values over $30 \mathrm{~kg} / \mathrm{m}^{2}$ indicate obesity.

\section{Statistical analysis}

Statistical analysis was conducted using Statistica software. Student's $t$-test, the Mann-Whitney $U$ test, and Spearman's correlation index $R$ were used.

\section{Results}

Table I presents analysed data in the control and experimental group.

Table I. Values of the analysed parameters in the examined groups of patients. ${ }^{\star} P<0.05$ between the rheumatoid arthritis patients and the control group

\begin{tabular}{|c|c|c|}
\hline Parameter & Control group & Experimental group - RA patients \\
\hline Number of participants (women) & 50 & 50 \\
\hline Age & $\begin{array}{c}31-61 \\
42.20 \pm 8.34\end{array}$ & $\begin{array}{c}32-69 \\
57.47 \pm 9.56\end{array}$ \\
\hline BMI & $25.64 \pm 2.33$ & $27.74 \pm 3.88$ \\
\hline Fat tissue mass [kg] & $23.14 \pm 4.20$ & $27.78 \pm 7.97$ \\
\hline Skeletal muscle mass [kg] & $25.54 \pm 5.86$ & $25.94 \pm 5.36$ \\
\hline Protein content [kg] & $9.16 \pm 1.65$ & $9.25 \pm 1.78$ \\
\hline$\%$ body fat (PBF) & $32.74 \pm 7.00$ & $36.35 \pm 8.00$ \\
\hline Foot Posture Index (FPI-6) & $0.48 \pm 0.82$ & $5.17 \pm 2.28$ \\
\hline Health Assessment Questionnaire (HAQ) & - & $1.72 \pm 0.54$ \\
\hline Disease Activity Score (DAS28) & - & $5.38 \pm 0.72$ \\
\hline \multicolumn{3}{|l|}{ Wejsflog's index (W) } \\
\hline Left foot & $2.79 \pm 0.14$ & $2.60 \pm 0.13^{*}$ \\
\hline Right foot & $2.81 \pm 0.18$ & $2.64 \pm 0.18^{*}$ \\
\hline \multicolumn{3}{|l|}{$\alpha$ angle } \\
\hline Left foot & $5.30 \pm 3.20$ & $17.34 \pm 5.44^{*}$ \\
\hline Right foot & $5.46 \pm 3.70$ & $17.08 \pm 4.47^{\star}$ \\
\hline \multicolumn{3}{|l|}{ Sztriter-Godunow's index (KY) } \\
\hline Left foot & $0.25 \pm 0.17$ & $0.43 \pm 0.19^{*}$ \\
\hline Right foot & $0.27 \pm 0.16$ & $0.44 \pm 0.17^{\star}$ \\
\hline \multicolumn{3}{|l|}{ Clarke's angle $(\mathrm{CL})$} \\
\hline Left foot & $61.50 \pm 10.46$ & $58.06 \pm 11.06$ \\
\hline Right foot & $62.52 \pm 14.53$ & $60.75 \pm 12.74$ \\
\hline
\end{tabular}

$R A$ - rheumatoid arthritis, BMI - body mass index. 
Statistical analysis of Wejsflog's index indicated significantly lower values for feet in the experimental group of patients than in the control group.

Statistically significantly higher values of $\alpha$ angle in both the left and right foot, reflecting hallux valgosity, were observed in experimental group (patients with RA). Also, statistically significantly higher KY values were observed in the same group.

Comparing RA patients with radiological stage I and II to healthy women revealed statistically significant differences in the Wejsflog index, the $\alpha$ angle and KY of the left and right foot (Table II). Similarly, we noted significant differences of the Wejsflog index and the $\alpha$ angle for feet between the experimental group with stage III and IV radiological changes and the control group (Table II). The Wejsflog index during the early phase RA (stage I and II radiological changes) and advanced RA (stage III and IV radiological changes) was statistically significantly lower than in the control group. No significant differences were observed among studied RA patients with regard to radiological stages. However, $\alpha$ angle had statistically significantly higher values in the early RA and increased together with the severity of radiological changes.

Similarly, we noted statistically significant differences in Wejsflog index, $\alpha$ angle, and KY index for feet between RA patients with different disease activity $3.2<$ DAS $28 \leq 5.1$ (moderate) and DAS $28>5.1$ (high) and the control group (Table III). In the studied group of patients with moderate and high DAS 28 a statistically significantly lower Wejsflog's index was observed in comparison to the control group.
However, the values of $\alpha$ angle were statistically significantly higher in the RA group and the highest value was noted in RA patients with DAS $28>5.1$.

The Sztriter-Godunow index was significantly higher in subgroups of RA in comparison to the control group.

Here, we observed a trend of an increase in $\alpha$ angle values and KY index in RA patients with increasing severity of the radiological changes and DAS-28.

No significant differences in the RA group with different disease activities were established with regard to selected stabilometric parameters.

\section{Correlations between body composition parameters and selected plantography examination parameters in rheumatoid arthritis patients}

Among the estimated parameters of foot statics, a negative correlation between the value of Wejsflog's index in the right foot, BMI value, and fat tissue mass was found.

\section{Correlations between foot static parameters and Foot Posture Index and Health Assessment Questionnaire in rheumatoid arthritis patients}

A positive correlation was noted between the Clarke's angle value for the left foot and the HAQ value.

No significant differences between foot static parameters and FPI-6 scale were noted.

Table II. Values of the selected stabilometric parameters in RA patients with radiological stage I/II and III/IV (data are given as mean $\pm \mathrm{SD}$ ). ${ }^{*} P<0.05$ between patients with stage I/II rheumatoid arthritis and the control group; between patients with stage III/IV and the control group

\begin{tabular}{|c|c|c|c|}
\hline Parameter & $\begin{array}{l}\text { Control group } \\
n=50\end{array}$ & $\begin{array}{l}\text { Patients with stage I/II RA } \\
\qquad n=28\end{array}$ & $\begin{array}{l}\text { Patients with stage III/IV RA } \\
\qquad n=22\end{array}$ \\
\hline \multicolumn{4}{|c|}{ Wejsflog's index (W) } \\
\hline Left foot & $2.79 \pm 0.14$ & $2.60 \pm 0.12^{*}$ & $2.61 \pm 0.15^{*}$ \\
\hline Right foot & $2.81 \pm 0.18$ & $2.64 \pm 0.16^{*}$ & $2.64 \pm 0.22^{*}$ \\
\hline \multicolumn{4}{|l|}{$\alpha$ angle } \\
\hline Left foot & $5.30 \pm 3.20$ & $16.68 \pm 4.65^{*}$ & $19.83 \pm 5.76^{*}$ \\
\hline Right foot & $5.46 \pm 3.70$ & $16.35 \pm 4.06^{*}$ & $17.08 \pm 4.47^{*}$ \\
\hline \multicolumn{4}{|c|}{ Sztriter-Godunow's index (KY) } \\
\hline Left foot & $0.25 \pm 0.17$ & $0.46 \pm 0.20^{*}$ & $0.40 \pm 0.16$ \\
\hline Right foot & $0.27 \pm 0.16$ & $0.48 \pm 0.20^{*}$ & $0.37 \pm 0.16$ \\
\hline \multicolumn{4}{|c|}{ Clarke's angle (CL) } \\
\hline Left foot & $61.50 \pm 10.46$ & $54.46 \pm 11.92$ & $63.48 \pm 7.06$ \\
\hline Right foot & $62.52 \pm 14.53$ & $57.29 \pm 14.01$ & $65.95 \pm 8.71$ \\
\hline
\end{tabular}

$R A$ - rheumatoid arthritis. 
Table III. Values of selected stabilometric parameters in patients with moderate and high disease activity (data are given as mean $\pm \mathrm{SD}$ ). ${ }^{*} P<0.05$ between rheumatoid arthritis patients with moderate and high disease activity and the control group

\begin{tabular}{|c|c|c|c|}
\hline Parameter & $\begin{array}{l}\text { Control group } \\
\quad n=50\end{array}$ & $\begin{array}{c}\text { Patients with } 3.2<\text { DAS28 } \\
\text { index } \leq 5.1 \\
\text { Moderate disease activity } \\
n=23\end{array}$ & $\begin{array}{c}\text { Patients with DAS28 } \\
\text { index }>5.1 \\
\text { High disease activity } \\
n=27\end{array}$ \\
\hline \multicolumn{4}{|c|}{ Wejsflog's index (W) } \\
\hline Left foot & $2.79 \pm 0.14$ & $2.57 \pm 0.11^{*}$ & $2.63 \pm 0.15^{*}$ \\
\hline Right foot & $2.81 \pm 0.18$ & $2.59 \pm 0.14^{*}$ & $2.68 \pm 0.21^{*}$ \\
\hline \multicolumn{4}{|l|}{$\alpha$ angle } \\
\hline Left foot & $5.30 \pm 3.20$ & $15.08 \pm 4.54^{*}$ & $19.08 \pm 5.55^{*}$ \\
\hline Right foot & $5.46 \pm 3.70$ & $15.52 \pm 3.45^{\star}$ & $18.27 \pm 4.88^{*}$ \\
\hline \multicolumn{4}{|c|}{ Sztriter-Godunow's index (KY) } \\
\hline Left foot & $0.25 \pm 0.17$ & $0.45 \pm 0.18^{*}$ & $0.42 \pm 0.19^{*}$ \\
\hline Right foot & $0.27 \pm 0.16$ & $0.50 \pm 0.16^{*}$ & $0.39 \pm 0.17^{*}$ \\
\hline \multicolumn{4}{|c|}{ Clarke's angle $(\mathrm{CL})$} \\
\hline Left foot & $61.50 \pm 10.46$ & $55.82 \pm 10.25$ & $59.78 \pm 11.66$ \\
\hline Right foot & $62.52 \pm 14.53$ & $56.45 \pm 15.93$ & $64.05 \pm 8.80$ \\
\hline
\end{tabular}

\section{Discussion}

Many patients with RA report foot symptoms at initial diagnosis and disturbances with postural control during everyday activities [4].

Nowadays, notwithstanding the development of medicine and advanced diagnostic methods, estimation of postural changes in the feet in the course of RA poses numerous difficulties. The generally used radiological examination does not always show the severity of clinical changes [16].

Plantar contourography examination is an objective tool to assess the static function and postural changes in the feet of RA patients [17]. This examination not only facilitates assessment of foot function, but it also gives proper diagnosis and graphic documentation of the results $[18,19]$.

There are studies describing the application of plantography examinations in detection of foot disturbances in RA patients [17, 20]. Researchers indicate that the results of plantography are precise and comparable [20-23].

In our present experiment, we applied plantar contourography to evaluate the foot static changes in an overweight RA population. To our knowledge this is the first study describing foot static disturbances in this population.

In the RA group, Wejsflog's index, hallux valgus angle (a), Sztriter-Godunov's index in both feet, and heel angle (g) in the left foot revealed the most common disturbances in foot statics.
The study by Puszczałowska-Lizis, which presented changes in foot statics in women aged 65-90 years, showed that mean values of Clarke's angle were $39.5^{\circ}$ for the right foot and $38.8^{\circ}$ for the left foot. The mean value of the hallux valgus for feet was $9^{\circ}$, and the value of the beta angle was $10^{\circ}$ [24].

In our experiments, values of Clarke's angle in the RA group were $60.75^{\circ}$ for the right foot and $58.06^{\circ}$ for the left foot. However, the highest values of Clarke's angle were observed in the subgroup of patients with advanced changes in the radiologic evaluation. The mean values of Clarke's angle in this subgroup were $65.5^{\circ}$ for the right foot and $63.48^{\circ}$ for the left.

In the present study, the highest values of hallux valgus angle (a) were observed in the subgroup of patients with advanced radiologic changes $-17.34^{\circ}$ for the left and $17.08^{\circ}$ for the right foot. In our previous study we revealed disturbances not only in the hallux valgus, but also in Clarke's angle and the KY index. Changes in these parameters significantly influence foot statics in RA patients [17].

As a continuation of experiments carried out in our clinic we decided to evaluate also RA patients with overweight. In the present examinations in overweight RA patients, we observed longitudinally flat feet in $46.6 \%$ of right feet and in $43.3 \%$ of left feet. But transverse flat foot was noted in $13 \%$ of right and in $10 \%$ of left feet. The presence of hallux valgus in the right foot was $100 \%$, while it was $97 \%$ in the left foot. 
Parcou reported that the risk and frequency of occurrence of static-dynamic foot disturbances are age-dependent. The author indicated that in consequence of involutional changes, changes in coping longitudinal foot arch and $\alpha$ angle were observed [25]. In the present study, there were significant differences between $\alpha$ angle in RA subgroups with different radiological stages. In the group with first and second degree radiological changes, the $\alpha$ angle mean value was $16.35^{\circ}$ for the right and $15.68^{\circ}$ for the left foot. In the group with third and fourth degree radiological changes, the values were higher $-18.18^{\circ}$ for the right and $19.83^{\circ}$ for the left foot.

Abundant scientific data have been collected regarding the problem of pathological foot changes. The estimation of dependence between longitudinal coping, transverse and setting of the hallux toe $\mathrm{V}$, and morphological structure and nutrition is a subject of interest [7-12, 14]. For the evaluation of nutritional status the BMI is used, but this parameter does not inform one of the fat tissue mass and non-fat body mass. There are no data concerning the connection between analysis of body composition parameters and foot static disturbances.

Examinations conducted on RA patients confirmed that there are often disturbances in body composition in these patients. It was shown that standard anthropometric estimations (i.e. body mass and BMI) are not sensitive enough to estimate changes in body composition.

Bioelectrical impedance analysis is a non-invasive, reliable and repetitive way to estimate body composition. This method demonstrates the precise estimation of protein, mineral substances, fat tissue, non-fat body mass, and water contained in the body.

Konijn et al. described differences between BMI and BIA (bioelectrical impedance). The authors observed high frequency of adverse body composition, mainly in the form of low muscle mass and increased fat tissue mass in RA patients. Additionally, according to BMI, the data showed that 54\% of patients were overweight or obese, and BIA in dicated that $74 \%$ of RA patients had a high or very high level of fat tissue; $18 \%$ had skeletal muscle mass below the norm [26]. Similar results were obtained in our research. A high or very high level of fat tissue was observed in $90 \%$ of patients, and $10 \%$ of patients had skeletal muscle mass below the norm.

Curyło et al. investigated the dependence between Wejsflog's index and BMI in 249 healthy people. They confirmed the correlation of BMI with Wejsflog's index. The results allowed them to estimate the frequency of transverse coping decline [27]. In our study, we found a statistically sig- nificant negative correlation between Wejsflog's index for the right foot and BMI value, as well as fat tissue mass value.

The mass of the body is one of many factors influencing proper function of the feet. Hills et al. observed increased plantar pressure and higher width of the front of the foot in obese people [28]. Lorkowski's experiment was carried out on obese women with plantar aponeurositis affecting both sides. In all of the women studied, he observed increased plantar pressure and presence of deformations [29].

Trzcińska used Clarke's angle and Sztriter-Godunov's index to estimate longitudinal foot arch and Wejsflog's index and heel angle to estimate transverse foot arch. She concluded that KY index disturbances in longitudinal foot arches were observed more often on the basis of Clarke's angle [30]. In our experiment, we observed more patients with flat feet on the basis of $K Y$ index estimation, and fewer when we used Clarke's angle criteria.

Applying Wejsflog's criteria, we noted a higher number of patients with transverse flat foot than when heel angle criteria were used. In the present study, we noted a negative relationship between the HAQ and feet function. In patients with RA, a high HAQ index can cause falls and fractures [6]. In addition to a positive correlation between the Clarke's angle of the left foot and HAQ index, we found a statistically significant positive correlation between DAS28, VAS, degree of X-ray changes and HAQ index.

Our results indicated the relationship between foot static changes and clinical course of RA in overweight patients. Here, we observed a trend of an increase in $\alpha$ angle values and $K Y$ index in RA patients with increasing severity of the radiological changes and DAS28. Plantar contourography and bioelectrical impedance can be useful for diagnostic examinations in overweight RA patients, improving diagnoses and ensuring use of proper therapeutic strategies of destructive changes.

\section{Conflict of interest}

The authors declare no conflict of interest.

\section{References}

1. Stanmore EK, Oldham J, Skeleton DA, et al. Risk factors for falls in adults with rheumatoid arthritis: a prospective study. Arthritis Care Res 2013; 65: 1251-8.

2. Scott DL, Wolfe F, Huizinga TWJ. Rheumatoid arthritis. Lancet 2010; 376: 1094-1108.

3. Gondal L, Tengstrand B, Nordmark B, Wretenberg P, Stark A. The foot: still the most important reason for walking incapacity in rheumatoid arthritis: distribution of symptomatic joints in 1000 RA patients. Acta Orthop 2008; 79: 257-61. 
4. Rome K, Dixon J, Gray M, Woodley R. Evaluation of static and dynamic postural stability in established rheumatoid arthritis: exploratory study. Clin Biomech 2009; 24: 524-6.

5. Villaroya MA, Esquivel JM, Tomas C, Moreno LA, Buenafe A, Bueno $\mathrm{G}$. Assessment of the medial longitudinal arch in children and adolescents with obesity: footprints and radiographic study. Eur J Pediatr 2009; 168: 559-67.

6. Tomaszewski K, Chmielewska K, Zarychta M, Galuszko P. Risk factors for falls and bone fractures in patients with rheumatoid arthritis. Reumatologia 2010; 48: 98-103.

7. Nikiphorou E, Norton S, Young A, et al. The association of obesity with disease activity, functional ability and quality of life in early rheumatoid arthritis: data from the Early Rheumatoid Arthritis Study/Early Rheumatoid Arthritis Network UK prospective cohorts. Rheumatology (Oxford) 2018; 57: 1194-1202.

8. Linauskas A, Overvad K, Symmons D, Johansen MB, Stengaard-Pedersen K, de Thurah A. Body fat percentage, waist circumference and obesity as risk factors for rheumatoid arthritis - a Danish cohort study. Arthritis Care Res (Hoboken) 2019; 71: 777-86.

9. Jawaheer D, Olsen J, Lahiff M, et al. Gender, body mass index and rheumatoid arthritis disease activity: results from the QUEST-RA Study. Clin Exp Rheumatol 2010; 28 454-61.

10. Ajeganova S, Andersson ML, Hafström I. BARFOT study Group Association of obesity with worse disease severity in rheumatoid arthritis as well as with comorbidities: a long-term follow up from disease onset. Arthritis Care Res (Hoboken) 2013; 65: 78-87.

11. Heimans L, van den Broek M, le Cessie S, et al. Association of high body mass index with decreased treatment response to combination therapy in recent-onset rheumatoid arthritis patients. Arthritis Care Res (Hoboken) 2013; 65: 1235-42.

12. Giles JT, Bartlett SJ, Andersen RE, Fontaine KR, Bathon JM. Association of body composition with disability in rheumatoid arthritis: impact of appendicular fat and lean tissue mass. Arthritis Rheum 2008; 59: 1407-15.

13. Kaufmann J, Kielstein V. Relation between body mass index and radiological progression in patients with rheumatoid arthritis. J Rheumatol 2003; 30: 2350-5.

14. Westhoff G, Rau R, Zink A. Radiographic joint damage in early rheumatoid arthritis is highly dependent on body mass index. Arthritis Rheum 2007; 56: 3575-82.

15. Mazidi M, Banach M, Kengne AP. Prevalence of childhood and adolescence overweight and obesity in Asian countries: a systematic review and meta-analysis. Arch Med Sci 2018; 14: 1185-1203.

16. de Rooy DP, van der Linden MP, Knevel R, Huizinga TW, van der Helm-van Mil AH. Predicting arthritis outcomes-what can be learned from the Leiden Early Arthritis Clinic? Rheumatology (Oxford) 2011; 50: 93-100.

17. Dzięcioł Z, Kuryliszyn-Moskal A, Dzięcioł J. Application of plantography examination to the assessment of foot deformity in patients with rheumatoid arthritis. Arch Med Sci 2015; 11: 1015-20.

18. Lizis $P$. The relationships of planta surface with features of the women's body. Pol J Physiother 2011; 11: 57-65.

19. Pinar B, Figen A, Figen T, Mehtap S. Foot problems in a group of patients with rheumatological arthritis: an unmet need for foot care. Open Rheumatol J 2012; 6: 290-5.

20. Kuryliszyn-Moskal A, Kaniewska K, Dzięcioł-Anikiej Z, Klimiuk PA. Evaluation of foot static disturbances in patients with rheumatic diseases. Reumatologia 2017; 55: 73-8.
21. Vidmar G, Novak P. Reliability of in-shoe plantar pressure measurements in rheumatoid arthritis patients. Int J Rehabil Res 2009; 32: 36-40.

22. Ma K, Li L, Liu Ch, Zhou L, Zhou X. Efficacy and safety of various anti-rheumatic treatments for patients with rheumatiod arthritis: a network meta-analysis. Arch Med Sci 2019; 15: 33-54.

23. Sadaf T, John P, Bhatti A, Malik JM. Lack of association of -863C/A (rs1800630) polymorphism of tumor necrosis factor- $\alpha$ gene with rheumatoid arthritis. Arch Med Sci 2019; 15: 531-6.

24. Puszczałowska-Lizis E. The relationships of Clarke's angle with strucural features of the forefoot and hindfoot and the prevalence of foot deformity in geriatric patients. Gerontol Pol 2011; 9: 33-9.

25. Parcou A. Middle, front mechanical metatarsalgia. Prevention. Shoes proactive. In: Dega W (ed.). Biomechanics and prophylaxis of static feet deformations. $1^{\text {st }}$ ed. Warszawa: PZWL; 1981. p 140-8.

26. Konijn NPC, Tuyl LHD, Bultink IEM, Lems WF, Earthman CP, Bokhorst-de van der Schueren MAE. Making the invisible visible: bioelectrical impedance analysis demonstrates unfavourable body composition in rheumatoid arthritis patients in clinical practice. Scand J Rheumatol 2014; 43: 273-8.

27. Curyło M, Wilk-Frańczuk M, Rynkiewicz-Androśkiewicz $M$, Raczkowski J. The impact of BMI value on the Wejsflog index, and the foot pain assessement. Pol J Physiother 2014; 14: 22-34.

28. Hills AP, Hennig EM, McDonald M, Bar-Or O. Plantar pressure differences between obese and non-obese adults: a biomechanical analysis. Int J Obes Relat Metab Disord 2001; 25: 1674-9.

29. Lorkowski J, Trybus M, Hładki W. Underfoot pressure distribution of a patient with unilateral ankylosis of talonavicular joint during rheumatoid arthritis - case report. Przegl Lek 2008; 65: 54-6.

30. Trzcińska D, Olszewska E, Tabor P. Analysis of foot arch in 16-year old students in the light of selected techniques of pantographic preparations. Adv Rehab 2007; 1: 7-13. 